\title{
Avatrombopag: A Review in Thrombocytopenia
}

\author{
Anthony Markham ${ }^{1}$
}

Accepted: 19 September 2021 / Published online: 28 October 2021

(c) Springer Nature 2021, corrected publication 2021

\begin{abstract}
Avatrombopag (Doptelet ${ }^{\circledR}$ ) is an orally administered second generation thrombopoietin receptor agonist (TPO-RA) approved for the treatment of primary chronic immune thrombocytopenia (ITP) in adult patients who are refractory or have an unsatisfactory response to other treatments, as well as for the treatment of thrombocytopenia in adult patients with chronic liver disease (CLD) scheduled to undergo an invasive procedure. In phase III studies, avatrombopag was associated with a significantly greater platelet response than placebo in patients with chronic ITP, and was superior to placebo in reducing the requirement for platelet transfusion or rescue procedures for bleeding caused by surgery in patients with CLD with a platelet count $<50 \times 10^{9} / \mathrm{L}$ at baseline. Longer term data indicate that avatrombopag is associated with high durable response rates in ITP and may have corticosteroid-sparing effects. The drug was generally well tolerated in both indications. Avatrombopag thus represents a convenient and effective second-line treatment for patients with chronic ITP and can prevent bleeding events in patients with CLD scheduled to undergo a procedure, offering a useful alternative to other available treatments in both indications.
\end{abstract}

\section{Plain Language Summary}

Avatrombopag (Doptelet ${ }^{\circledR}$ ) is an orally administered drug that mimics the natural compound (thrombopoietin) responsible for stimulating the production of platelets, an essential component of the clotting process that prevents excessive bleeding. Several conditions can cause reduced platelet levels (thrombocytopenia) to the point that intervention is needed to prevent excessive blood loss. Avatrombopag is approved for the treatment of primary chronic immune thrombocytopenia (ITP) and to prevent bleeding caused by surgery in patients with low platelet levels caused by chronic liver disease (CLD). Clinical trials in patients with ITP show that avatrombopag quickly increases platelet levels and that this increase is maintained in the longer term in many patients. Similarly, clinical trials in patients with low platelet levels because of CLD showed that giving avatrombopag prior to surgery reduced the need for platelet transfusions or rescue procedures for bleeding. Avatrombopag is thus a convenient and effective treatment for patients with chronic ITP and can prevent bleeding events in patients with CLD scheduled to undergo a procedure. In both indications avatrombopag offers a useful alternative to other available treatments.

Digital Features for this AdisInsight Report can be found at https://doi.org/10.6084/m9.figshare.16626412.

The manuscript was reviewed by: A. Ascione, Department of Internal Medicine, Centre for Liver Disease, Buon ConsiglioFatebenefratelli Hospital, Naples, Italy; $\boldsymbol{R}$. Maan, Department of Gastroenterology and Hepatology, Erasmus MC University Medical Center, Rotterdam, Netherlands.

Anthony Markham

demail@springer.com

1 Springer Nature, Private Bag 65901, Mairangi Bay, Auckland 0754, New Zealand
Avatrombopag: clinical considerations in thrombocytopenia

Second-generation TPO-RA

Associated with durable improvements in platelet count in patients with ITP

Effective in reducing the need for platelet transfusion or rescue procedures for bleeding in patients with CLDassociated thrombocytopenia undergoing procedures

Generally well tolerated 


\section{Introduction}

Thrombocytopenia-defined as a platelet count below $150 \times 10^{9} / \mathrm{L}$ - can arise in several circumstances and increases the risk of excessive bleeding, particularly after surgery [1]. Immune thrombocytopenia (ITP), an acquired autoimmune disorder resulting from immune-mediated platelet destruction and impaired platelet production, is estimated to affect two to five persons per 100,000 [2]. Thrombocytopenia is also relatively common in patients with chronic liver disease (CLD), with a prevalence of $15-90 \%$, generally rising as the severity of disease increases [3, 4]. Other causes of thrombocytopenia include pregnancy, certain cancers and cancer treatments, aplastic anaemia and certain viral infections including HIV infection [1].

Treatment for ITP should aim to improve platelet count such that the risk of bleeding is reduced with minimal treatment-related adverse events [5]. In patients who are nonresponsive to first-line treatments (such as corticosteroids, IV immunoglobulin and anti-D) or who are corticosteroiddependent, a number of second- and third-line treatment options are available including splenectomy, rituximab (offlabel), fostamatinib and thrombopoietin receptor agonists (TPO-RAs) [2]. Splenectomy is effective but is an invasive procedure associated with a life-long risk of complications. Rituximab and fostamatinib are less effective than splenectomy and fostamatinib has mainly been evaluated in patients who have received two or more previous therapies. TPORAs are associated with a higher durable response rate than splenectomy, rituximab or fostamatinib [2].

Patients with severe thrombocytopenia (defined as a platelet count $\left.<50 \times 10^{9} / \mathrm{L}\right)$ associated with CLD are at increased risk of bleeding during or after invasive therapeutic procedures. Platelet transfusions have been the primary tool for the management of thrombocytopenia in these patients; they are, however, limited by potential transfusion reactions and the potential development of antiplatelet antibodies (alloimmunization). This has led to interest in alternative approaches such as TPO-RAs, which offer a convenient, non-invasive means of increasing platelet levels [6].

Avatrombopag (Doptelet ${ }^{\circledR}$ ) is an orally administered second generation TPO-RA approved in the USA [7] and the EU [8] for the treatment of primary chronic ITP in adult patients who are refractory to (EU) or have had insufficient response to (USA) other treatments; the drug is also approved in the USA for the treatment of thrombocytopenia in adult patients with CLD who are scheduled to undergo a procedure, and in the EU for the treatment of severe thrombocytopenia in adult patients with CLD who are scheduled to undergo an invasive procedure. This review summarises the pharmacological properties of avatrombopag and its therapeutic efficacy and tolerability in ITP, and as treatment for thrombocytopenia in patients with CLD scheduled to undergo a procedure.

\section{Pharmacodynamic Properties of Avatrombopag}

The endogenous ligand thrombopoietin is the primary regulator of platelet production, mainly via stimulation of megakaryocyte growth. Its receptor is expressed on many haematopoietic cells, including stem cells, megakaryocyte colony forming cells and mature platelets, and exists as a dimer, with each monomer containing two cytokine receptor homology domains. Thrombopoietin binds to only the distal domain, activating the receptor and initiating several signal transduction pathways, notably JAK/STAT, but also MAPK and various anti-apoptotic pathways [9]. In vitro, avatrombopag induced proliferation of human thrombopoietin receptor-expressing murine $\mathrm{Ba} / \mathrm{F} 3$ cells in a concentration-dependent manner $\left(\mathrm{EC}_{50} 3.3 \mathrm{nmol} / \mathrm{L}\right)$, with maximal activity similar to that of recombinant human thrombopoietin (rhTPO). Ba/F3 cells not expressing the thrombopoietin receptor did not respond to the drug, demonstrating that its activity depends on the presence of the receptor [10]. Further analysis revealed avatrombopag induced tyrosine phosphorylation of STAT3 and STAT5, and threonine phosphorylation of MAPK (ERK) in these cells (Fig. 1).

Avatrombopag also promoted megakaryocyte differentiation from human cord blood CD34+ cells in a concentration-dependent manner $\left(\mathrm{EC}_{50} 25.0 \mathrm{nmol} / \mathrm{L}\right)$, with maximum activity similar to that of rhTPO. Human megakaryocyte colonies generated with avatrombopag had similar morphologic features to those generated with rhTPO. In G-CSF-mobilized human peripheral blood CD34+ cells cultured with a combination of avatrombopag and rhTPO, megakaryocyte proliferation was $\approx 200 \%$ greater than that seen with rhTPO alone. Proliferation of haematopoietic and megakaryocytic progenitor cells was also greater with the combination than with avatrombopag or rhTPO alone, indicating an additive effect early in the maturation process. In human platelets ex vivo, the presence of avatrombopag had no effect on the binding of radiolabelled rhTPO to the TPO receptor, indicating the drug binds to a different site on the receptor than the endogenous ligand [11].

In vivo in non-obese diabetic/severe combined immunodeficiency mice transplanted with human fetal liver CD34+ cells, oral administration of avatrombopag produced a dosedependent increase in human platelet count [10].

On the basis that thrombopoietin has been shown to lower the threshold for platelet activation, the effect of avatrombopag on platelets taken from patients with CLD participating in the phase III ADAPT-1 and ADAPT-2 studies (Sect. 4.2) has been investigated. Treatment with avatrombopag was associated with increased platelet counts but no increase in platelet activation or platelet reactivity was observed [12]. 


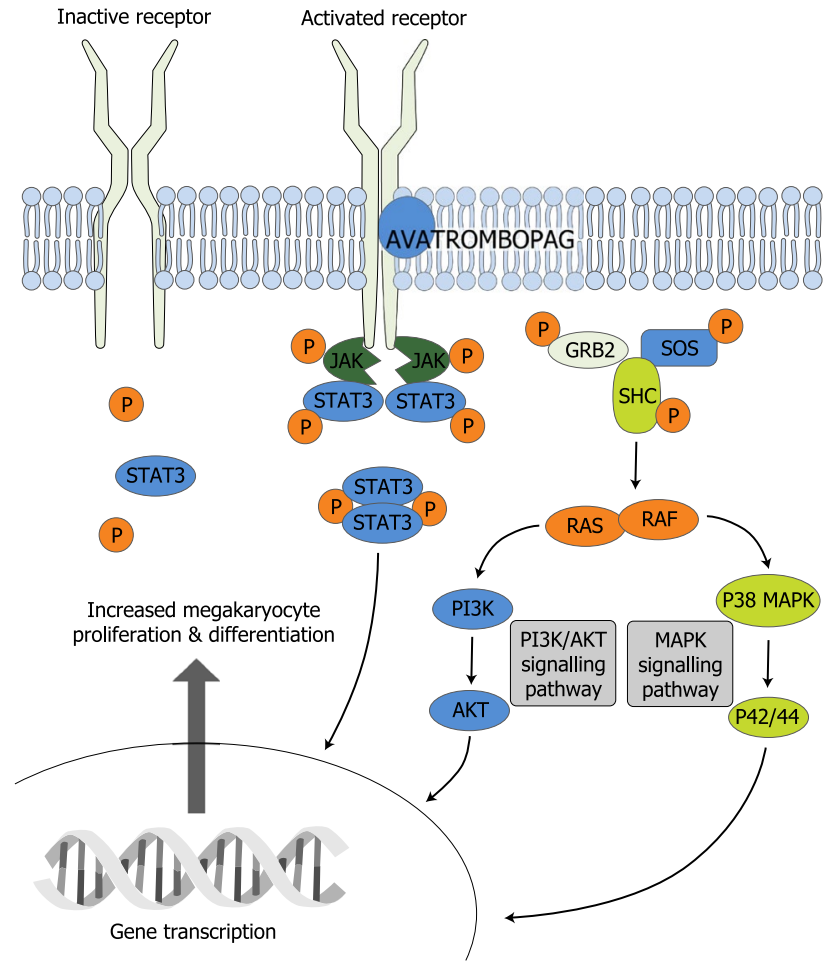

Fig 1 Mechanism of action of avatrombopag

\section{Pharmacokinetic Properties of Avatrombopag}

Avatrombopag was absorbed slowly after oral administration to volunteers, with a short lag time $(0.5-0.75 \mathrm{~h})$ and time to maximum plasma concentration of 6-8 h, with steady state reached by day 5 in a multiple dose study. Exposure increased in a dose-proportional manner up to a dose of $80 \mathrm{mg}$. Maximum plasma concentrations $\left(\mathrm{C}_{\max }\right)$ and the area under the plasma concentration-time curve (AUC) were not affected to a clinically important extent when avatrombopag was given with high or low fat food; however, between and within subject variability in $\mathrm{C}_{\max }$ and AUC was reduced by $\approx 50 \%$ and it is thus recommended that the drug is administered with food [8, 13].

Avatrombopag is $>96 \%$ bound to human plasma proteins according to in vitro data. Based on a population pharmacokinetic analysis, the drug has an apparent volume of distribution of $\approx 235 \mathrm{~L}$ in patients with chronic ITP and $\approx 180 \mathrm{~L}$ in patients with thrombocytopenia and CLD, indicating extensive distribution [8].

Avatrombopag is metabolized primarily by cytochrome P450 (CYP) 2C9 and CYP3A, with unchanged drug and metabolites excreted mostly in faeces $(88 \%)$, and no metabolites detected in plasma. The terminal half-life $\left(\mathrm{t}_{1 / 2}\right)$ is $\approx 19 \mathrm{~h}$ [8].

In a drug-drug interaction study in volunteers $(n=48)$, coadministration of a single $20 \mathrm{mg}$ dose of avatrombopag with the dual CYP2C9 and CYP3A inhibitor fluconazole was associated with $\mathrm{a} \approx 2$-fold increase in avatrombopag AUC and an approximate doubling in $t_{1 / 2}$, which led to a clinically relevant 1.66 -fold increase in platelet count. The effect of the strong CYP3A inhibitor itraconazole on the pharmacokinetic profile of avatrombopag was relatively mild compared to fluconazole, indicating that CYP2C9-mediated metabolism predominates. Coadministration of a single $20 \mathrm{mg}$ dose of avatrombopag with the dual CYP2C9 and CYP3A inducer rifampin was associated with $\mathrm{a} \approx 0.5$-fold decrease in AUC and an approximate halving of $t_{1 / 2}$, although this did not have a clinically relevant effect on platelet count [14].

The pharmacokinetic profile of avatrombopag was best described by a one-compartment model with simultaneous first- and zero-order absorption, and linear elimination according to a population pharmacokinetic analysis of data from 787 patients and volunteers participating in phase I studies, as well as phase II and III studies in patients with thrombocytopenia associated with CLD. Bodyweight and the presence of CLD were found to have a significant effect on apparent volume of distribution, and East Asian ethnicity, and increasing albumin and thrombopoietin levels significantly reduced the effect of avatrombopag on platelet production; however, these effects were not considered clinically relevant [13].

\section{Therapeutic Efficacy of Avatrombopag}

\subsection{Chronic Immune Thrombocytopenia}

The efficacy of oral avatrombopag as treatment for chronic ITP has been investigated in two multicentre, double-blind, phase III trials, the first comparing the drug to placebo [15] and the second to oral eltrombopag [16]. The trial comparing avatrombopag with eltrombopag, however, was terminated before completion because of enrolment challenges related to the requirement for endoscopy and availability of eltrombopag, and no conclusions could be drawn [17]. Prior to these trials the utility of avatrombopag in this indication was established in a phase II dose-finding study and extension [18], which is not discussed further.

In the placebo-controlled study, patients with chronic $(\geq 12$ months in duration) ITP and low platelet count at baseline (average of two platelet counts $<30 \times 10^{9} / \mathrm{L}$ ) were randomized to 6 months' treatment with placebo $(n=17)$ or avatrombopag. Avatrombopag was given at an initial dose of $20 \mathrm{mg}$ once daily, then titrated to minimum and maximum doses of 5 and $40 \mathrm{mg} /$ day according to response $(n=32)$. After 26 weeks, patients who did not go on to participate in a subsequent open-label extension stage (described below) entered a dose tapering phase 
(4 weeks) with a further 4 weeks' follow-up. Exclusion criteria included secondary ITP, clinically significant arterial or venous thrombosis, cardiovascular disease, chronic active hepatitis, cirrhosis, gastric atrophy, malignant disease, myelodysplastic syndrome, pernicious anaemia or portal hypertension, and recent use of romiplostim or eltrombopag. The protocol allowed for concurrent use of other standard-of-care treatments for chronic ITP, and rescue therapy. Forty-seven percent of avatrombopag and $41 \%$ of placebo recipients were receiving concomitant ITP medication at baseline and $34 \%$ and $29 \%$, respectively, had undergone splenectomy.

Twenty-two patients in the avatrombopag group and one in the placebo group completed the study, with 7 and 15, respectively, discontinuing because of lack of efficacy. Avatrombopag was superior to placebo in terms of the cumulative mean number of weeks of platelet response (defined as a platelet count $\geq 50 \times 10^{9} / \mathrm{L}$ ) without needing rescue therapy (primary endpoint; 12 weeks vs 0.1 weeks [ $p<0.0001]$ ). Twenty-one $(65.6 \%)$ avatrombopag recipients had a platelet response at day 8 compared to no patients in the placebo group ( $p<0.0001$, Table 1$)$. Durable response (no requirement for rescue therapy, and response in $\geq 6$ of the final 8 weeks) was observed in $34.4 \%$ of avatrombopag recipients versus no patients in the placebo group $(p<0.009)$ [15].

Further endpoints were evaluated in post hoc analyses [19]. These included clinically relevant response (median number of weeks with no requirement for rescue therapy and a platelet count threshold of $\geq 30 \times 10^{9} / \mathrm{L}$ [21.1 in the avatrombopag group vs 0 in the placebo group]), and reduction in corticosteroid use (of 14 avatrombopag and 7 placebo recipients receiving corticosteroid therapy at baseline, 6 and 0 , respectively, were able to discontinue corticosteroid therapy, and 1 and 0 , respectively, were able to reduce their corticosteroid dose).

The efficacy of avatrombopag was maintained in an extension phase of this trial. After completing the placebocontrolled phase of the study (or discontinuing treatment because of lack of efficacy), patients had the option to continue treatment with avatrombopag (maximum duration of exposure in both phases 76 weeks) [15]. In a post hoc analysis, the proportion of study visits during the extension phase with a platelet count of $\geq 50 \times 10^{9} / \mathrm{L}$ was $44.1 \%$ in patients treated with avatrombopag in the core study and $41.3 \%$ in patients switched to avatrombopag from placebo. Complete platelet response (platelet count $\geq 100 \times 10^{9} / \mathrm{L}$ ) was achieved at $24.1 \%$ of visits in patients initially randomized to avatrombopag and $18.3 \%$ of visits in patients switched from placebo to avatrombopag. Patients who had a durable response in the double-blind phase had response at $60.1 \%$ of the extension phase visits. One patient who received avatrombopag in the core study and three switched from placebo to avatrombopag were able to discontinue corticosteroid therapy, and none and two, respectively, were able to reduce their corticosteroid dose [19].

\subsection{Thrombocytopenia Associated with Chronic Liver Disease Prior to an Elective Procedure}

The efficacy of avatrombopag as treatment for thrombocytopenia associated with CLD prior to an elective procedure has been established in the phase III ADAPT program, comprising the global ADAPT-1 and ADAPT-2 studies [20]. These were identically designed, randomized, double-blind, multicentre, placebo-controlled studies, with the primary endpoint being the proportion of patients who did not require a platelet transfusion or rescue procedure for bleeding after treatment assignment and for up to 7 days after a scheduled procedure. Patients with CLD (Model for End-Stage Liver Disease [MELD] score $\leq 24)$ and thrombocytopenia were stratified according to low $\left(<40 \times 10^{9} / \mathrm{L}\right)$ or high (40 to $\left.<50 \times 10^{9} / \mathrm{L}\right)$ baseline platelet count and given avatrombopag 60 or $40 \mathrm{mg}$ once daily, respectively, or matching placebo, for 5 days. These dosages were selected based on pharmacokinetic/pharmacodynamic modelling and simulations derived from data from a phase II study that evaluated various avatrombopag regimens (which is not discussed further) [21]. Exclusion criteria included a history of thrombosis, haematological disorders, significant cardiovascular disease, portal or splenic mesenteric system thrombosis, portal vein blood flow $<10 \mathrm{~cm} / \mathrm{s}$, advanced hepatocellular carcinoma (HCC) and use of interventions within 7 days of screening likely to influence the study outcome (e.g. platelet transfusion, heparin, warfarin, antiplatelet therapy, erythropoietinstimulating agents). In the low baseline platelet count cohort, 160 patients (90 in ADAPT-1 and 70 in ADAPT-2) were randomized to avatrombopag and 91 (48 in ADAPT-1 and 43 in ADAPT-2) to placebo. In the high baseline platelet count group, 117 patients (59 in ADAPT-1 and 58 in ADAPT-2) were randomized to avatrombopag and 67 (34 in ADAPT-1 and 33 in ADAPT-2) to placebo [20].

In both studies avatrombopag was superior to placebo in increasing the proportion of patients who did not require a platelet transfusion or rescue procedure for bleeding. Approximately two thirds of avatrombopag recipients in the low baseline platelet count cohorts achieved this primary endpoint compared to 23\% (ADAPT-1) and 35\% (ADAPT2 ) of placebo recipients ( $p \leq 0.0006)$ (Table 2$)$. In the high baseline platelet count cohorts, close to $90 \%$ of avatrombopag recipients achieved the primary endpoint compared to $38 \%$ (ADAPT-1) and 33\% (ADAPT-2) of placebo recipients $(p<0.0001)$ [Table 2]. The proportion of patients achieving the target platelet count $\left(\geq 50 \times 10^{9} / \mathrm{L}\right)$ on procedure day was significantly higher in avatrombopag versus placebo recipients in both the low and high baseline platelet count cohorts in both studies ( $p<0.0001$ for all comparisons). The mean change in platelet count from baseline to procedure day in both the low and high baseline platelet count cohorts 
Table 1 Efficacy of avatrombopag in chronic immune thrombocytopenia in a 6-month phase III trial [15]

\begin{tabular}{lllll}
$\begin{array}{l}\text { Treatment } \\
\text { pts randomized) }\end{array}$ & $\begin{array}{l}\text { Mean cumulative wks of PLT } \\
\text { response }^{\mathrm{a}}(\text { range) }\end{array}$ & $\begin{array}{l}\text { Pts with PLT response } \\
\text { day } 8\end{array}$ & $\begin{array}{l}\text { Pts with } \downarrow \text { use of concomitant ITP } \\
\text { medications from baseline }\end{array}$ & $\begin{array}{l}\text { Durable PLT } \\
\text { response rate }^{\mathrm{c}}\end{array}$ \\
\hline AVA $(n=32)$ & $12^{\mathrm{d}}(0,25)^{*}$ & $21(65.6 \%)^{*}$ & $5 / 15(33 \%)$ & $34.4 \% * *$ \\
\hline PL $(n=17)$ & $0.1^{\mathrm{d}}(0,2)$ & $0(0.0 \%)$ & $0 / 7(0 \%)$ & $0.0 \%$ \\
\hline
\end{tabular}

AVA avatrombopag, ITP chronic immune thrombocytopenia, $P L$ placebo, $P L T$ platelet, pts patients, $\downarrow$ decreased

$* p<0.0001, * * p<0.009$

a Platelet count $\geq 50 \times 10^{9} / \mathrm{L}$ in the absence of rescue therapy

${ }^{\mathrm{b}}$ Only patients receiving concomitant ITP medications at baseline included

${ }^{\mathrm{c}}$ Proportion of patients who had a platelet response for $\geq 6$ of the last 8 weeks

of treatment

${ }^{\mathrm{d}}$ Primary endpoint

was also significantly higher in avatrombopag recipients compared to the placebo group in both studies $[p<0.0001$ for all comparisons] (Table 2) [20].

An integrated analysis of pooled data from the two ADAPT studies found that avatrombopag was significantly more effective than placebo in reducing the requirement for platelet transfusions or rescue procedures in both the low and high baseline platelet count cohorts $(66.9 \%$ vs $28.6 \%$ in the low and $88 \%$ vs $35.8 \%$ in the high baseline platelet count groups with avatrombopag and placebo, respectively, both $p<0.0001$ ). Importantly, most patients $(93.8 \%)$ who responded to avatrombopag had platelet counts $\geq 50 \times 10^{9} / \mathrm{L}$ on the day of the procedure compared to $38.0 \%$ of placebo recipients [6].

Sub-analysis of data from patients participating in ADAPT- 1 and 2 found that the efficacy of avatrombopag was not affected by bleeding risk when procedures were divided according to low (paracentesis, endoscopy, colonoscopy), moderate (liver biopsy, ethanol ablation, chemoembolization for HCC) or high (dental, transjugular intrahepatic portosystemic shunt [TIPS], laparoscopy, radio-ablation, vascular catheterization) risk of bleeding. Avatrombopag was more effective than placebo in terms of the primary endpoint in all three risk categories $(84.0 \%$ vs $40.7 \%$ in procedures with low bleeding risk, $75.6 \%$ vs $31.0 \%$ in moderate and $70.5 \%$ vs $20.7 \%$ in high). The number of patients achieving the primary endpoint was also consistently higher in avatrombopag versus placebo recipients regardless of age, gender, ethnicity, geographic region, MELD score category, Child-Turcotte-Pugh class, or liver disease aetiology [6, 20].

\section{Tolerability of Avatrombopag}

\subsection{Chronic Immune Thrombocytopenia}

Avatrombopag was generally well tolerated in patients with ITP. Pooled safety data from the two phase III trials described above (Sect 4.1) and two phase II trials (a double-blind, placebo-controlled, dose-finding trial and an open-label extension trial) included data from a total of 128 patients treated with avatrombopag $2.5-40 \mathrm{mg}$ once daily for 29.1 (median) weeks who had one post-dose safety assessment, and 22 placebo recipients. Adverse reactions occurring with a frequency of $\geq 10 \%$ included headache ( $31 \%$ with avatrombopag vs $14 \%$ with placebo), fatigue ( $28 \%$ vs $9 \%$ ), contusion ( $26 \%$ vs $18 \%$ ), epistaxis (19\% vs $18 \%)$, upper respiratory tract infection (15\% vs $5 \%$ ), arthralgia (13\% vs $0 \%$ ), gingival bleeding ( $13 \%$ vs $0 \%$ ), petechiae (11\% vs $9 \%$ ) and nasopharyngitis (10\% vs $0 \%)$. Twelve patients (9\%) treated with avatrombopag experienced adverse events considered serious, most frequently headache (1.6\%; two patients). Adverse reactions occurring in more than one patient that required discontinuation of avatrombopag included headache, occurring in two patients (1.6\%) [7]. A total of 11 thromboembolic events occurred in nine patients treated with avatrombopag (7\%) including two patients (1.6\%) with cerebrovascular accident [8]. These tended to occur at platelet counts below the upper bound of normal $\left(450 \times 10^{9} / \mathrm{L}\right)$ and no relationship between the duration of exposure to the drug and the occurrence of thromboembolic events was evident [22]. In the phase III study, the overall incidence of treatmentemergent adverse events was $96.9 \%$ ( 31 of 32 patients) in avatrombopag recipients compared to $58.8 \%$ (10 of 17 patients) with placebo; however, no clinically important difference was observed when incidence rates were adjusted for exposure (4.3\% per patient-week with avatrombopag vs $6.6 \%$ per patient-week with placebo) [15].

Long-term use of TPO-RAs has been linked to the development or progression of reticulin fibres/fibrosis within the bone marrow, although the clinical importance of this observation is unknown. During the clinical development programme for avatrombopag, 1 of $128(<1 \%)$ patients with ITP developed $2+$ bone marrow reticulin fibrosis with focal areas of $3+\approx 1$ month after avatrombopag therapy was discontinued. The patient received 161 days of treatment with avatrombopag and prior to this had received eltrombopag for 56 days. Bone marrow reticulin fibrosis was also elevated (1+) prior to treatment [23]. 
Table 2 Efficacy of avatrombopag in patients with thrombocytopenia associated with chronic liver disease

\begin{tabular}{|c|c|c|c|c|}
\hline Study & Treatment & $\begin{array}{l}\text { Pts not requiring PLT transfusion } \\
\text { or rescue }^{\mathrm{a}}\end{array}$ & $\begin{array}{l}\text { Pts achieving PLT count } \\
\geq 50 \times 10^{9} / \mathrm{L}\end{array}$ & $\begin{array}{l}\text { Mean } \Delta \text { in PLT } \\
\text { count }\left(\times 10^{9} / \mathrm{L}\right)\end{array}$ \\
\hline \multicolumn{5}{|c|}{ ADAPT-1 [20] } \\
\hline & AVA $40 \mathrm{mg}$ od $\times 5 \mathrm{~d}(n=59)^{\mathrm{b}}$ & $88.1 \% *$ & $88.1 \% *$ & $37.1 *$ \\
\hline & $\mathrm{PL}(n=34)^{\mathrm{b}}$ & $38.2 \%$ & $20.6 \%$ & 1 \\
\hline & AVA $60 \mathrm{mg}$ od $\times 5 \mathrm{~d}(n=90)^{\mathrm{c}}$ & $65.6 \% *$ & $68.9 \% *$ & $32^{*}$ \\
\hline & $\operatorname{PL}(n=48)^{\mathrm{c}}$ & $22.9 \%$ & $4.2 \%$ & 0.8 \\
\hline \multicolumn{5}{|c|}{ ADAPT-2 [20] } \\
\hline & AVA $40 \mathrm{mg}$ od $\times 5 \mathrm{~d}(n=58)^{\mathrm{b}}$ & $87.9 \% *$ & $93.1 \% *$ & $44.9 *$ \\
\hline & $\operatorname{PL}(n=33)^{\mathrm{b}}$ & $33.3 \%$ & $39.4 \%$ & 5.1 \\
\hline & AVA $60 \mathrm{mg}$ od $\times 5 \mathrm{~d}(n=70)^{\mathrm{c}}$ & $68.6 \% * *$ & $67.1 \% *$ & $31.3^{*}$ \\
\hline & $\operatorname{PL}(n=43)^{\mathrm{c}}$ & $34.9 \%$ & $7.0 \%$ & 3 \\
\hline
\end{tabular}

Results from the phase III ADAPT-1 and ADAPT-2 studies

$A V A$ avatrombopag, $o d$ once daily, $P L$ placebo, $P L T$ platelet, pts patients, $\Delta$ change

$* p<0.0001$ versus PL, $* * p=0.0006$ versus PL

${ }^{\text {a }}$ Primary endpoint

${ }^{\mathrm{b}}$ High baseline platelet count cohort

${ }^{c}$ Low baseline platelet count cohort

\subsection{Thrombocytopenia Associated with Chronic Liver Disease Prior to an Elective Procedure}

The incidence of treatment-emergent adverse events was relatively low in the pooled safety analysis set $(n=430)$ from the ADAPT-1 and 2 studies (Sect. 4.2). The overall incidence of treatment-emergent adverse events in avatrombopag recipients was similar to that in placebo recipients in both the avatrombopag $60 \mathrm{mg} /$ day (low baseline platelet count; $56.0 \%$ and $58.2 \%$, respectively) and avatrombopag $40 \mathrm{mg} /$ day (high baseline platelet count; $51.3 \%$ and $50.8 \%$, respectively) treatment cohorts. The incidence of treatmentemergent adverse events considered to be treatment-related was $11.3 \%$ in the avatrombopag $60 \mathrm{mg} /$ day cohort versus $17.6 \%$ with placebo, and $7.0 \%$ in the avatrombopag $40 \mathrm{mg} /$ day cohort versus $6.2 \%$ with placebo. The most frequent treatment-emergent adverse events ( $\geq 3 \%$ to $11.3 \%$ ) included pyrexia, abdominal pain, nausea, headache, procedural pain, fatigue and peripheral oedema $[6,7]$. The overall incidence of serious treatment-emergent adverse events was $7.3 \%$ in avatrombopag recipients compared to $9.0 \%$ with placebo. These included acute myocardial infarction and disseminated intravascular coagulation/pulmonary embolus (one placebo recipient each), gastrointestinal haemorrhage and hyponatraemia (in two avatrombopag recipients each) and partial portal vein thrombosis (in one avatrombopag recipient) [6]. The latter was the only thromboembolic event observed in patients treated with avatrombopag in these trials [8].

\section{Dosage and Administration of Avatrombopag}

In patients with ITP the recommended starting dose of avatrombopag is $20 \mathrm{mg}$ once daily then titrated to achieve a stable platelet count between $\geq 50$ and $\leq 150 \times 10^{9} / \mathrm{L}$, with platelet levels assessed at least once weekly; consult local prescribing information for details of dose titration and discontinuation of treatment criteria [7, 8].

In patients with CLD, the recommended dose of avatrombopag is $60 \mathrm{mg}$ once daily (in patients with a platelet count $<40 \times 10^{9} / \mathrm{L}$ ) or $40 \mathrm{mg}$ once daily (in patients with a platelet count between 40 and $<50 \times 10^{9} / \mathrm{L}$ ) for 5 days starting between 10 and 13 days before the planned procedure, with the last dose taken 5-8 days before the procedure. Platelet counts should be obtained prior to administration of avatrombopag and on the day of a procedure to ensure a satisfactory increase in platelet count has occurred [7, 8].

Because of the potential for platelet counts to exceed $400 \times 10^{9} / \mathrm{L}$ within the first weeks of treatment with avatrombopag, patients should be monitored for signs or symptoms of thrombocytosis. After a stable platelet count has been achieved, platelet counts should be obtained at least monthly. After discontinuation of avatrombopag, platelet counts should be obtained weekly for at least 4 weeks [8].

Local prescribing information should be consulted for detailed information, including recommended dosage modifications according to platelet levels, monitoring requirements, precautions, warnings and use in special populations. Avatrombopag should not be given to patients with ITP or CLD in an attempt to normalise platelet counts [8]. 


\section{Place of Avatrombopag in the Management of Thrombocytopenia}

Minimization of the use of corticosteroids because of tolerability concerns is a key aspect of management guidelines for ITP, with corticosteroid use suggested only when platelet counts drop below $30 \times 10^{9} / \mathrm{L}$ in patients who are asymptomatic or have minor bleeding, and then only in short $(<6$ weeks total) courses [2]. Although a small proportion of patients are able to tolerate prolonged low-dose corticosteroid therapy, alternative subsequent treatment options are required for most. Here, the primary aim is a sustained increase in platelet levels with minimal adverse events, while preserving the prospect of remission. As described in the introduction (Sect. 1) various second and third-line treatment options are available. Of these, splenectomy, once the gold standard, is now generally reserved for third-line treatment [2]. Chronic treatment with fostamatinib has demonstrated efficacy in studies in patients who had nearly all received 2-3 previous therapies [24] but its role as secondline treatment has not been fully established [2]. In addition, hypertension-related adverse reactions were observed in $\approx 25 \%$ of patients receiving fostamatinib in these trials, leading to a requirement for regular blood pressure monitoring, and potential dosage adjustments, in patients treated with this drug [25].

TPO-RAs approved for use in ITP include avatrombopag, eltrombopag and romiplostim-lusutrombopag is not approved in this indication. While both eltrombopag and romiplostim are associated with a higher durable response rate than splenectomy [2], romiplostim is administered as a once weekly SC injection and cannot be administered orally and, unlike avatrombopag, eltrombopag requires dietary restrictions. Avatrombopag was superior to placebo in producing a durable increase in platelet counts in patients with chronic ITP in a phase III trial and extension (Sect. 4.1), with a second phase III study comparing avatrombopag to eltrombopag unfortunately terminated before any meaningful conclusions could be drawn. As such studies comparing avatrombopag to an active comparator would be of value. In the absence of such head-to-head studies, a network metaanalysis found that avatrombopag was associated with a significantly lower incidence of bleeding events than eltrombopag (incidence rate ratio 0.38 [ $95 \%$ credible interval 0.19 , $0.75]$ ) and romiplostim (incidence rate ratio 0.38 [95\% credible interval $0.17,0.86]$ ), but not fostamatinib, in patients with chronic ITP and an inadequate response to corticosteroids [26]. In addition, a retrospective analysis has indicated that avatrombopag is effective in patients previously treated with eltrombopag or romiplostim [27], and a phase IV study evaluating treatment satisfaction in patients switching from eltrombopag or romiplostim to avatrombopag is currently underway [28]. A phase IV study evaluating the real world use of avatrombopag (ADOPT) is pending [29].

Avatrombopag as treatment for ITP is generally well tolerated with an adverse event profile similar to that of placebo when adjusted for duration of treatment exposure [15]. The reported overall rates and severity of adverse events appear to be generally similar to that seen with other TPO-RAs with no new or unique adverse events occurred in avatrombopag recipients that had not been previously observed in patients treated with eltrombopag [30] or romiplostim [31]. Unlike eltrombopag, however, avatrombopag has not been associated with clinically significant hepatotoxicity [30].

The increased risk of bleeding associated with thrombocytopenia in patients with CLD can complicate diagnostic or therapeutic procedures. Available data indicate the risk of bleeding in patients with platelet counts $\geq 50 \times 10^{9} / \mathrm{L}$ undergoing invasive procedures is minimal; however, the risk of bleeding in patients with more severe thrombocytopenia (platelet count $\leq 20 \times 10^{9} / \mathrm{L}$ ) is unclear. Platelet transfusions are widely used to mitigate the risk of bleeding in patients with CLD and thrombocytopenia with recommended cutoff values varying considerably (from $<20 \times 10^{9} / \mathrm{L}$ to $<100 \times 10^{9} / \mathrm{L}$ ), depending on the procedure planned and comorbidity status $[32,33]$. Risks associated with platelet transfusions include transfusion reactions, bacterial sepsis and the potential for diminished response to subsequent platelet transfusions (refractoriness) [33, 34], with the likelihood of complications increasing with repeated transfusions. Platelets are also a scarce resource and can only be stored for a short time [35].

Alternatives to platelet transfusion include one-off procedures such as splenectomy, partial splenic artery embolization, radiofrequency ablation of the spleen, TIPS and administration of TPO-RA inhibitors prior to surgery [36]. Of the latter, avatrombopag and lusutrombopag are approved for use in this indication whereas romiplostim and eltrombopag are not. As described above, the utility of splenectomy is limited by associated surgical complications. Partial splenic artery embolization can be effective but platelet counts tend to decline over time, and nearly all patients will experience post-embolization syndrome requiring hospitalization, with rates of serious complications ranging between 15 and 30\% [37]. Radiofrequency ablation of the spleen is a relatively recent advance with limited data as to its long-term effectiveness [38]. TIPS has been shown to significantly increase platelet count in some studies but not others, and no predictors of response have been identified [39]. TPO-RAs, on the other hand, are an effective, orally-administered, non-invasive method of increasing platelet levels in patients with CLD with an increased risk of bleeding prior to diagnostic and therapeutic procedures, and offer a longer treatment window than platelet transfusion [35]. In the phase III ADAPT studies, a short course of avatrombopag was superior to placebo in increasing the proportion of patients 
who did not require a platelet transfusion or rescue procedure for bleeding (Sect. 4.2), and had a similar tolerability profile (Sect. 5.2). In addition, a retrospective analysis of real-world data has found that avatrombopag increased platelet count by procedure day, with platelet transfusion required in only 1 of 50 procedures reviewed [40]. In the absence of a head-to-head study comparing avatrombopag and lusutrombopag in this indication, a network meta-analysis has found that more avatrombopag than lusutrombopag recipients achieved a platelet count $\geq 50 \times 10^{9} / \mathrm{L}$ (odds ratio 3.40 [95\% credible intervals 1.41 to 8.34]) with no significant between-treatment differences for other efficacy or safety outcomes revealed [41]. In a cost-efficacy analysis, avatrombopag was predicted to produce cost savings compared to platelet transfusions and lusutrombopag from a third-party US payer perspective in patients with thrombocytopenia associated with CLD scheduled to undergo an invasive procedure [42]. UK NICE guidance recommends the use of avatrombopag as an option (along with lusutrombopag) for treating severe thrombocytopenia in adults with CLD who have a planned invasive procedure [35] and posit that use of avatrombopag would highly likely reflect a good use of scarce NHS resources [35].

In conclusion, available data indicate avatrombopag is effective and well tolerated as second-line treatment for patients with chronic ITP, and to prevent bleeding events in patients with CLD during procedures. In patients with ITP, avatrombopag was associated with durable response rates and evidence of corticosteroid-sparing effects after long-term follow-up. In patients with CLD, avatrombopag rapidly increased platelet levels and significantly reduced the need for platelet transfusions or rescue procedures. In both indications avatrombopag can be considered a useful alternative to other available treatments.

\section{Data Selection Avatrombopag: 306 records} identified

Duplicates removed

Excluded during initial screening (e.g. press releases; news reports; not relevant drug/indication; preclinical study; reviews; case reports; not randomized trial)

Excluded during writing (e.g. reviews; duplicate data; small patient number; nonrandomized/phase I/II trials)

Cited efficacy/tolerability articles

Search Strategy: EMBASE, MEDLINE and PubMed from 1946 to present. Clinical trial registries/databases and websites were also searched for relevant data. Key words were avatrombopag, Doptelet, thrombocytopenia. Records were limited to those in English language. Searches last updated 17 Sep 2021
Supplementary Information The online version contains supplementary material available at https://doi.org/10.1007/s40265-021-01613-y.

Acknowledgements During the peer review process, the manufacturer of avatrombopag was also offered an opportunity to review this article. Changes resulting from comments received were made on the basis of scientific and editorial merit.

\section{Declarations}

Funding The preparation of this review was not supported by any external funding.

Authorship and Conflict of interest A. Markham is a salaried employee of Adis International Ltd/Springer Nature, and declares no relevant conflicts of interest. All authors contributed to the review and are responsible for the article content.

Ethics approval, Consent to participate, Consent to publish, Availability of data and material, Code availability Not applicable.

Open Access This article is licensed under a Creative Commons Attribution-NonCommercial 4.0 International License, which permits any non-commercial use, sharing, adaptation, distribution and reproduction in any medium or format, as long as you give appropriate credit to the original author(s) and the source, provide a link to the Creative Commons licence, and indicate if changes were made. The images or other third party material in this article are included in the article's Creative Commons licence, unless indicated otherwise in a credit line to the material. If material is not included in the article's Creative Commons licence and your intended use is not permitted by statutory regulation or exceeds the permitted use, you will need to obtain permission directly from the copyright holder. To view a copy of this licence, visit http://creativecommons.org/licenses/by-nc/4.0/.

\section{References}

1. Kuter D. MSD manual: professional version; overview of platelet disorders. 2020. https://www.msdmanuals.com/professional/ hematology-and-oncology/thrombocytopenia-and-platelet-dysfu nction/overview-of-platelet-disorders. Accessed 17 Sep 2021.

2. Neunert C, Terrell DR, Arnold DM, et al. American Society of Hematology 2019 guidelines for immune thrombocytopenia. Blood Adv. 2019;3(23):3829-66.

3. Giannini EG. Review article: thrombocytopenia in chronic liver disease and pharmacologic treatment options. Aliment Pharmacol Ther. 2006;23(8):1055-65.

4. Qamar AA, Grace ND, Groszmann RJ, et al. Incidence, prevalence, and clinical significance of abnormal hematologic indices in compensated cirrhosis. Clin Gastroenterol Hepatol. 2009;7(6):689-95.

5. Provan D, Arnold DM, Bussel JB, et al. Updated international consensus report on the investigation and management of primary immune thrombocytopenia. Blood Adv. 2019;3(22):3780-817.

6. Poordad F, Terrault NA, Alkhouri N, et al. Avatrombopag, an alternate treatment option to reduce platelet transfusions in patients with thrombocytopenia and chronic liver disease-integrated analyses of 2 phase 3 studies. Int J Hepatol. 2020;2020:5421632.

7. Swedish Orphan Biovitrum. Doptelet ${ }^{\circledR}$ (avatrombopag): US prescribing information. 2020. https://doptelet.com/themes/pdf/presc ribing-information.pdf. Accessed 17 Sep 2021. 
8. Swedish Orphan Biovitrum. Doptelet ${ }^{\circledR}$ (avatrombopag): EU summary of product characteristics. 2021. https://www.ema.europa. eu/. Accessed 17 Sep 2021.

9. Kuter DJ. The biology of thrombopoietin and thrombopoietin receptor agonists. Int J Hematol. 2013;98(1):10-23.

10. Fukushima-Shintani M, Suzuki K, Iwatsuki Y, et al. AKR-501 (YM477) a novel orally-active thrombopoietin receptor agonist. Eur J Haematol. 2009;82(4):247-54.

11. Fukushima-Shintani M, Suzuki K, Iwatsuki Y, et al. AKR-501 (YM477) in combination with thrombopoietin enhances human megakaryocytopoiesis. Exp Hematol. 2008;36(10):1337-42.

12. Michelson AD, Smolensky Koganov E, Forde EE, et al. Avatrombopag increases platelet count but not platelet activation in patients with thrombocytopenia resulting from liver disease. $\mathbf{J}$ Thromb Haemost. 2018;16(12):2515-9.

13. Nomoto M, Ferry J, Hussein Z. Population pharmacokinetic/pharmacodynamic analyses of avatrombopag in patients with chronic liver disease and optimal dose adjustment guide with concomitantly administered CYP3A and CYP2C9 inhibitors. J Clin Pharmacol. 2018;58(12):1629-38.

14. Nomoto M, Zamora CA, Schuck E, et al. Pharmacokinetic/pharmacodynamic drug-drug interactions of avatrombopag when coadministered with dual or selective CYP2C9 and CYP3A interacting drugs. Br J Clin Pharmacol. 2018;84(5):952-60.

15. Jurczak W, Chojnowski K, Mayer J, et al. Phase 3 randomised study of avatrombopag, a novel thrombopoietin receptor agonist for the treatment of chronic immune thrombocytopenia. Br J Haematol. 2018;183(3):479-90.

16. US National Institutes of Health. NCT01433978. 2021. https:// clinicaltrials.gov/. Accessed 17 Sep 2021.

17. Tarantino MD, Vredenburg M, Tian W, et al. Efficacy analyses from the immune thrombocytopenia (ITP) clinical development program for avatrombopag: comparisons with placebo and eltrombopag [abstract]. Blood. 2020;136(Suppl. 1):23-4.

18. Bussel JB, Kuter DJ, Aledort LM, et al. A randomized trial of avatrombopag, an investigational thrombopoietin-receptor agonist, in persistent and chronic immune thrombocytopenia. Blood. 2014;123(25):3887-94.

19. Al-Samkari H, Nagalla S. Efficacy and safety evaluation of avatrombopag in immune thrombocytopenia: analyses of a phase III study and long-term extension. Platelets. 2021. https://doi.org/10. 1080/09537104.2021.1881952.

20. Terrault N, Chen YC, Izumi N, et al. Avatrombopag before procedures reduces need for platelet transfusion in patients with chronic liver disease and thrombocytopenia. Gastroenterology. 2018;155(3):705-18.

21. Terrault NA, Hassanein T, Howell CD, et al. Phase II study of avatrombopag in thrombocytopenic patients with cirrhosis undergoing an elective procedure. J Hepatol. 2014;61(6):1253-9.

22. Piatek CI, Jamieson B, Vredenburg M. Characterization of thromboembolic events occurring during the avatrombopag immune thrombocytopenia (ITP) clinical development program [abstract no. 844]. Blood. 2020;136(Suppl 1):39.

23. Swedish Orphan Biovitrum. EU summary of the risk management plan for Doptelet ${ }^{\circledR}$. 2021. https://www.ema.europa.eu/. Accessed 17 Sep 2021.

24. Bussel J, Arnold DM, Grossbard E, et al. Fostamatinib for the treatment of adult persistent and chronic immune thrombocytopenia: results of two phase 3, randomized, placebo-controlled trials. Am J Hematol. 2018;93(7):921-30.
25. Instituto Grifols SA. Tavlesse ${ }^{\circledR}$ (fostamatinib): EU summary of product characteristics. 2020. https://www.ema.europa.eu/. Accessed 17 Sep 2021.

26. Wojciechowski P, Wilson K, Nazir J, et al. Efficacy and safety of avatrombopag in patients with chronic immune thrombocytopenia: a systematic literature review and network meta-analysis. Adv Ther. 2021. https://doi.org/10.1007/s12325-021-01752-4.

27. Al-Samkari H, Jiang D, Gernsheimer T, et al. A multicenter U.S. study of avatrombopag switch therapy following prior eltrombopag or romiplostim [abstract no. EP1141]. In: European Hematology Association Virtual Congress. 2021.

28. US National Institutes of Health. NCT04638829. 2021. https:// clinicaltrials.gov/. Accessed 17 Sep 2021.

29. US National Institutes of Health. NCT04943042. 2021. https:// clinicaltrials.gov/. Accessed 17 Sep 2021.

30. Novartis Europharm Ltd. Revolade ${ }^{\circledR}$ (eltrombopag): EU summary of product characteristics. 2021. https://www.ema.europa. eu/. Accessed 17 Sep 2021.

31. Amgen Europe B.V. Nplate ${ }^{\circledR}$ (romiplostim): EU summary of product characteristics. 2021. https://www.ema.europa.eu/. Accessed 17 Sep 2021.

32. Afdhal N, McHutchison J, Brown R, et al. Thrombocytopenia associated with chronic liver disease. J Hepatol. 2008;48(6):1000-7.

33. Blumberg N, Heal JM, Phillips GL. Platelet transfusions: trigger, dose, benefits, and risks. F1000 Med Rep. 2010;2:5.

34. Slichter SJ, Davis K, Enright H, et al. Factors affecting posttransfusion platelet increments, platelet refractoriness, and platelet transfusion intervals in thrombocytopenic patients. Blood. 2005;105(10):4106-14.

35. UK National Institute for Health and Care Excellence. Avatrombopag for treating thrombocytopenia in people with chronic liver disease needing a planned invasive procedure. 2020. https://www. nice.org.uk/guidance/ta626. Accessed 17 Sep 2021.

36. Gangireddy VG, Kanneganti PC, Sridhar S, et al. Management of thrombocytopenia in advanced liver disease. Can J Gastroenterol Hepatol. 2014;28(10):558-64.

37. Hadduck TA, McWilliams JP. Partial splenic artery embolization in cirrhotic patients. World J Radiol. 2014;6(5):160-8.

38. Feng K, Ma K, Liu Q, et al. Randomized clinical trial of splenic radiofrequency ablation versus splenectomy for severe hypersplenism. Br J Surg. 2011;98(3):354-61.

39. Massoud OI, Zein NN. The effect of transjugular intrahepatic portosystemic shunt on platelet counts in patients with liver cirrhosis. Gastroenterol Hepatol (N Y). 2017;13(5):286-91.

40. Satapathy S, Jamieson B. Real-world use of avatrombopag in patients with severe thrombocytopenia associated with chronic liver disease undergoing a procedure [abstract no. PO-2634]. J Hepatol. 2021;75(Suppl 2):1.

41. Wojciechowski P, Wilson K, Pochopien M, et al. Comparative efficacy and safety of avatrombopag versus lusutrombopag in patients with chronic LIVER disease and severe thrombocytopenia undergoing invasive procedures: a systematic literature review and network meta-analysis [abstract no. PDB34]. In: International Society for Pharmacoeconomics and Outcomes. 2021.

42. Mladsi D, Barnett C, Aggarwal K, et al. Cost-effectiveness of avatrombopag for the treatment of thrombocytopenia in patients with chronic liver disease. Clinicoecon Outcomes Res. 2020;12:515-26. 